\title{
Factors concerned in the efficient steam sterilization of surgical dressings
}

\author{
R. J. FALLON \\ From the University Department of Bacteriology, Western Infirmary, Glasgow ${ }^{1}$
}

SYNOPSIS Some of the factors affecting the efficient steam sterilization of dressings have been examined. A jacketed sterilizer will process a load more quickly than a sterilizer without a jacket. The level of fore-vacuum is critical and must reach an absolute pressure of $20 \mathrm{~mm} . \mathrm{Hg}(29 \cdot 2 \mathrm{in} . \mathrm{Hg}$ vacuum) or less. This will overcome all conditions of overpacking studied. The level of after-vacuum should be $100 \mathrm{~mm}$. $\mathrm{Hg}$ absolute or less, preferably near $50 \mathrm{~mm}$. $\mathrm{Hg}$ absolute.

Overpacking cannot be defined in terms of weight of a fabric per unit volume of container but occurs when a load is compressed in its container.

It is surprising that, despite the recent important changes in design of steam sterilizers, little critical published work has appeared relating to the principles underlying these changes. The high prevacuum, high-pressure sterilizer is now regarded as the best steam sterilizer available and yet there is no substantial experimental work to encourage the use of steam at a pressure of 30 to 32 pounds per square inch (p.s.i.); indeed doubts have been expressed as to the wisdom of using this pressure as opposed to lower levels (Knox, 1961). Since the original work of Knox and Penikett (1958) on the level of forevacuum to be employed in high pre-vacuum sterilization no detailed confirmation of their results has been presented, although suggestive supportive evidence is available (Magee and Oakes, 1958; Alder and Gillespie, 1959; Wells and Whitwell, 1960).

A high pre-vacuum contributes to the efficient steam sterilization of dressings, i.e., a process which produces a dry, sterile load in the shortest possible time without damage to the load. Other factors which contribute to efficiency are effective drying of the load with which must be bracketed a good supply of dry, saturated steam, prevention of the load being recontaminated by unsterile air at the end of the process, and finally any modification to a sterilizer which increases its rate of turnover.

In the present study the factors concerned with the efficiency of such sterilizers which have been considered are: Speed of sterilization in relation to whether a sterilizer should be jacketed or unjacketed,

${ }^{1}$ Now at Pathology Department, Ruchill Hospital, Glasgow.

Received for publication 17 May 1961. effective removal of air by high pre-vacuum, and drying of a load. Finally, as downward-displacement sterilizers are still widely used some studies have been made on the efficiency of the downward-displacement method of removing air.

\section{THE EXPERIMENTAL STERILIZER}

The sterilizer used was a cylindrical, horizontal dressings sterilizer of $4 \cdot 2$ cubic $\mathrm{ft}$. capacity. Steam was supplied from the hospital main supply at a pressure of 60 to 65 pounds per square inch gauge (p.s.i.) and passed through a separator to a reducing valve which reduced the pressure to 20 p.s.i. The steam was supplied at this pressure to the jacket and chamber independently. Steam entered the chamber at the back and was deflected by a baffle plate. The chamber drain was situated at the front of the chamber and served also as the point from which the vacuum was drawn by a steam jacketed, oil-sealed, airballasted pump. A steam ejector was also fitted. This drew its vacuum through the steam-to-chamber steam pipe.

The oil-sealed vacuum pump, which was designed to pump water vapour and air, was connected to the chamber drain by a pipe which was heated to prevent steam from condensing in it before reaching the pump. The pump usually took about five minutes to reduce the chamber pressure from atmospheric to $20 \mathrm{~mm}$. $\mathrm{Hg}$ absolute pressure. The chamber drain led through a hand-operated valve, a non-return valve, and a balanced-pressure thermostatic steam trap to a tundish.

\section{INSTRUMENTATION}

TEMPERATURE Fourteen metal-sheathed, copper constantan thermocouples $1 / 16$ inch $(0.159 \mathrm{~cm}$.) in diameter were led through the sterilizer door. It was found that they could be threaded through a silicone rubber bung held in 


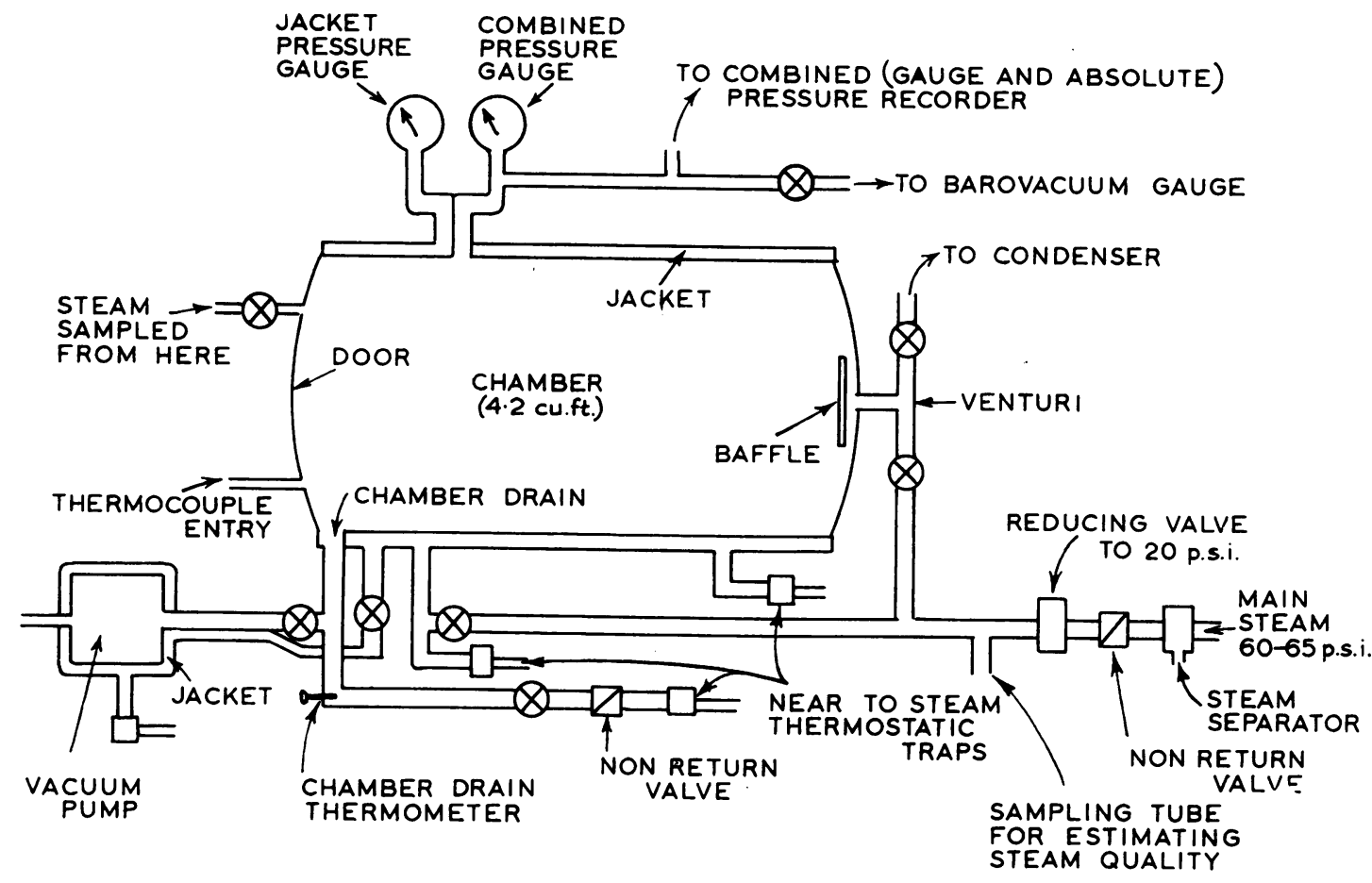

FIG. 1. Diagram of experimental sterilizer and pump.

a valve gland screwed into the door without causing any vacuum leakage. Another thermocouple was inserted into the chamber drain line $12 \mathrm{in}$. from the chamber. These thermocouples were connected to a 16-point highspeed electronic recorder. The temperature registered by each thermocouple was printed on a chart, there teing a five-second interval between each successive recording. Hence the temperature at any single point was recorded once every 80 seconds. The recorder was calibrated from $30^{\circ}$ to $140^{\circ} \mathrm{C}$. in $2^{\circ} \mathrm{C}$. divisions, the overall accuracy being $0.5 \%$. In practice the temperature was read to the nearest degree Centigrade except during calibration runs.

The thermocouples were calibrated from time to time against a mercury-in-glass thermometer using an oil bath. Their speed of response was such that a full-scale deflection could be obtained inside the five-second interval between the printing of the recorder. The effect of heat conduction along the thermocouples leads on the accuracy of recording was found to be negligible.

PRESSURE AND VACUUM RECORDING Jacket pressure was indicated on a Bourdon gauge. The chamter pressure was indicated on a comtined pressure and vacuum gauge and was recorded on a combined gauge and absolute-pressure recorder. The degree of vacuum was also ascertained by a mercury baro-vacuum gauge. This latter gave a direct reading in millimetres of mercury absolute pressure and was therefore independent of variations in barometric pressure.
LOADS Most experiments were carried out using 20 in. $\times$ 30 in. cotton huck towels, each folded into 12 thicknesses. For most experiments these towels were placed, in varying numbers, inside cylindrical dressing drums (10 in diameter $\times 9$ in. deep), which were lined with a further two such towels in order to simulate drum liners. The drums had 14 groups of 16 holes $5 / 32$ in. in diameter spaced round the circumference.

Thermocouples were introduced into the loads in such a way that when the drums were placed in the sterilizer the thermocouples entered from the bottom of the drum, i.e., in the opposite direction to that from which steam would enter the load by downward displacement of air. The delay in temperature rise seen in many experiments suggested that steam did not track alongside the thermocouples.

\section{CONFIRMATION OF DEGREE OF VACUUM NECESSARY FOR RAPID STEAM PENETRATION INTO A LOAD}

For the purposes of comparing the effect of different degrees of fore-vacuum on steam penetration, a load which was only slowly penetrated by steam by the downward displacement method was used. This, it was thought, should show well any delay in steam penetration due to an inadequate fore-vacuum. The load chosen consisted of 16 towels (plus a further two lining the drum), each fo'dcd into 12 thicknesses and so placed that the layers of towel lay in a horizontal plane when the drum was posi- 


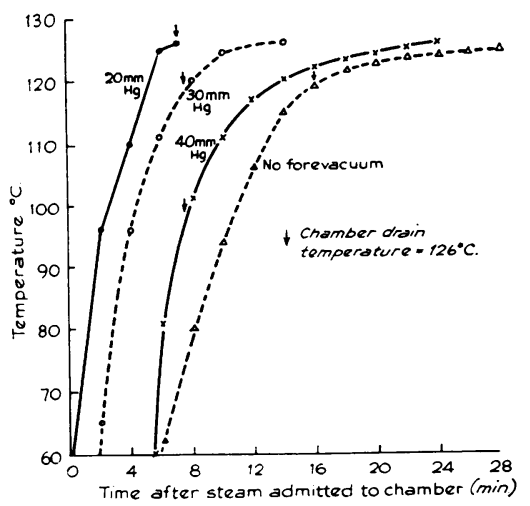

FIG. 2. Effect of different degrees of fore-vacuum on temperature rise in coolest part of load after admission of steam to chamber.

tioned correctly, i.e., on its side, in the sterilizer. Thermocouples were introduced from the bottom of the load as positioned in the sterilizer and were placed in the same position in each experiment.

In these experiments the chamber was evacuated to the desired extent, steam was admitted, and the temperature rise in different parts of the load was noted. The slowest rises in temperature in experiments using different degrees of fore-vacuum are shown in Fig. 2.

It can be seen that, with a fore-vacuum giving a pressure of $20 \mathrm{~mm} . \mathrm{Hg}$ absolute, the temperature inside the load rose rapidly once steam was admitted to the chamber, and reached $126^{\circ} \mathrm{C}$. (the temperature of saturated steam corresponding to the gauge pressure of 20 p.s.i.) at the same time as the chamber drain thermometer. With a fore-vacuum of only $30 \mathrm{~mm}$. $\mathrm{Hg}$ absolute, however, there was a delay in steam penetration and with a fore-vacuum down to $40 \mathrm{~mm}$. $\mathrm{Hg}$ absolute $(28.4 \mathrm{in}$. $\mathrm{Hg}$ vacuum at a barometric pressure of $30 \mathrm{in}$. $\mathrm{Hg}-\mathrm{a}$ level of vacuum offered by some sterilizer manufacturers) the time taken for steam to penetrate the load differed but little from that taken by downward displacement.

The critical nature of the level of fore-vacuum necessary to obtain almost instantaneous steam penetration into a load was thus demonstrated. Further experiments showed that even with a load of 29 folded towels where the drum lid had to be forced shut, a fore-vacuum down to $20 \mathrm{~mm}$. $\mathrm{Hg}$ absolute enabled steam to penetrate the load instantaneously.

These findings confirm the conclusions of Knox and Penikett (1958). The method used in the present observations differed from that used by Knox and Penikett in that the time required to reach saturated steam temperature in the load was examined on each occasion instead of that required to reach an arbitrary temperature of $115^{\circ} \mathrm{C}$. Both sets of observations agree, however, and make it clear that any high-vacuum sterilizer which fails to achieve a fore-vacuum down to at least $20 \mathrm{~mm}$. $\mathrm{Hg}$ absolute pressure is potentially dangerous, because if the sterilization process is timed from the chamber drain temperature the cycle may be completed before the load has been penetrated by steam.

Apart from inability to draw an adequate fore-vacuum the high vacuum sterilization process may be defeated by a rather more subtle fault.

If air can leak into the chamber between the time when the vacuum pump is disconnected from the chamber and the steam pressure reaches zero gauge, steam penetration into the load may be slow (Fallon, 1961a). This fault will tend to be obscured by a powerful vacuum pump which will overcome small leaks and will be revealed only by monitoring of a load in the sterilizer either by Browne's tubes or thermocouples. It might be revealed by a careful inspection of the chart showing the time taken to reach the final level of fore-vacuum. Hence a daily inspection of charts from such a sterilizer and the immediate investigation of any deviation from normal is highly important, as is emphasized in the M.R.C. report (1959).

\section{THE DEGREE OF AFTER-VACUUM}

Dressings after sterilization can be rapidly and effectively dried merely by drawing an after-vacuum down to $50 \mathrm{~mm}$. $\mathrm{Hg}$ absolute (Penikett, Rowe, and Robson, 1958). However, these authors state that in their experiments the load achieved a moisture content of less than $5 \%$ and was by their definition 'dry' when the pressure in the chamber was reduced to about $300 \mathrm{~mm}$. $\mathrm{Hg}$ (18 in. of vacuum) with a single drum or $200 \mathrm{~mm}$. $\mathrm{Hg}(21 \mathrm{in}$.) with a full load of dressings without the vacuum being held. As they note, this level of after-vacuum may readily be obtained in many sterilizers at present installed in hospitals. It is evident that if merely drawing an after-vacuum of the order of $18 \mathrm{in} . \mathrm{Hg}$ without any airing of the load will give dry dressings, the dangers of recontamination of a load associated with prolonged airing through inadequate filters and of damage to the load due to prolonged contact with hot air would be avoided. In view of the importance of this subject the findings of Penikett et al. were reexamined.

In any experiments on the moisture uptake of dressings it is important that the steam entering the chamber should be of good quality. The quality of steam supplied to the experimental sterilizer was measured at two sites by different methods.

THROTTLING CALORIMETRY The quality of steam in the 20 p.s.i. supply line was measured by this method. Steam was sampled by means of a horizontal pipe, of the same diameter as the steam line, leading to a diaphragm in the centre of which was a hole 1/64 in. diameter $(0.0397$ $\mathrm{cm}$.). The dryness fraction of the steam could be calculated from the temperature of the steam issuing from this hole to atmospheric pressure. The steam in the supply line had a dryness fraction of $\mathbf{0 . 9 8}$.

BUCKET CALORIMETRY The method used was similar to that described by Penikett et al. (1958) except that the steam in the chamber was sampled through a hole bored in the sterilizer door, the steam being led through a welllagged tube to a Dewar flask. The steam sampled from 
this site may well have given a lower dryness fraction than that which actually obtained in the chamber, due to the continual condensation of steam when it met the relatively cool door with the possible formation of some water fog at that point. The quality of the steam was measured with loads actually in the chamber. Eleven estimations gave a mean value of 0.90 (standard deviation 0.04).

The discrepancy between the two results suggests that despite lagging of the steam line some condensation had taken place in the steam before it entered the chamber but the fact that steam was sampled from the door and in the presence of a load would also play a part.

\section{EXPERIMENTAL}

Loads to be sterilized consisted of cotton huck towels placed in the dressing drum so that the folds lay in a vertical plane if downward displacement sterilization was being studied. In high vacuum studies the drums were placed on their base to reproduce the conditions used by Penikett et al. (1958).

Towels were sterilized in drums or packs and were weighed, immediately before and after sterilization, on a balance which could be read to the nearest gram. Between experiments the towels were placed on a rack and their moisture content was allowed to equilibrate with that of the air in the hospital. Before any run the relative humidity of the atmosphere was determined using a wet- and dry-bulb thermometer. The relative humidity ranged from $36 \%$ to $77 \%$, an average level being about $53 \%$. There was no constant relationship between the relative humidity and the weight of towels on any one day.

It was found that the moisture gain of a load was always greater on the first sterilizing run of the day so that all experiments reported here were carried out after the sterilizer had been used for one or more runs so that the door and back of the sterilizer as well as the steam lines were thoroughly hot.

Sterilizing runs were carried out with and without a preliminary fore-vacuum. In most cases the steaming period was for 10 minutes after the chamber pressure reached 20 p.s.i. but in some experiments longer periods of steaming were carried out to see if this had any effect on the moisture content of a load. Some experiments were carried out to see whether the residual moisture content was related to the type of container used. At the end of the steaming period different degrees of aftervacuum, produced rapidly by the oil-sealed pump, were applied. The vacuum was broken rapidly (in less than $30 \mathrm{sec}$.) as soon as the appropriate level was reached and the load was then removed from the sterilizer and container and was weighed immediately. Errors due to the temperature of the load would in fact be negligible and it was also observed that the loss of moisture through evaporation was not so rapid as to render accurate weighing difficult because the balance used was well damped and read almost instantaneously.

RESULTS

The results using eight cotton huck towels (plus two

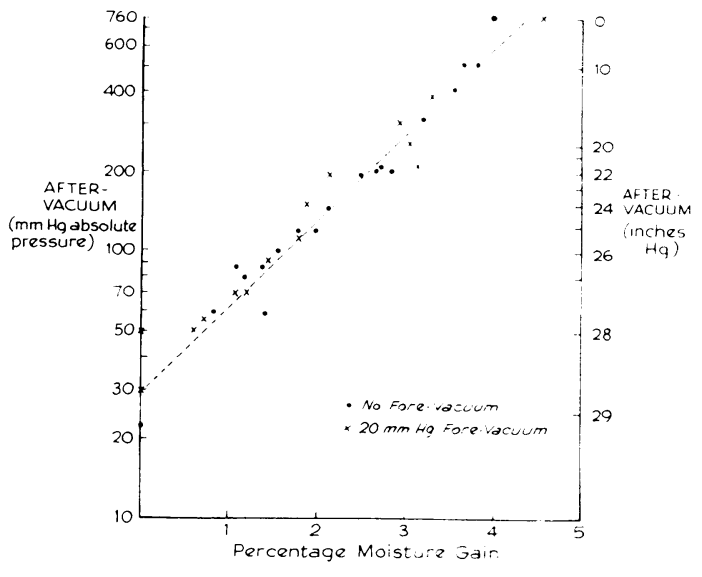

FIG. 3. The relationship between after-vacuum ( $\log$ scale) and percentage moisture gain is approximately linear.

lining the drum) are shown in Fig. 3 in which the percentage moisture gain is plotted against the after-vacuum applied. It can be seen that although there was some scatter in the results obtained by weighing, the relationship between the degrees of after-vacuum (plotted logarithmically) and the percentage moisture gain was roughly linear and that if the final absolute pressure reached during the vacuum phase was above $100 \mathrm{~mm}$. $\mathrm{Hg}$ (26 in. $\mathrm{Hg}$ vacuum) the moisture gain would generally be greater than $1.5 \%$. There was little difference whether a high pre-vacuum or downward-displacement method of sterilization was used.

With the towels used in these experiments it was found that their moisture content averaged about $4.5 \%$ before sterilization so that a gain in moisture of over $1.5 \%$ would mean that the towels would be subjectively damp (Penikett et al., 1958). Experiments with tightly packed drums containing 20 to 25 towels showed that the moisture gain was only slightly higher than that in loosely packed drums but that in the few experiments conducted with packs of eight towels wrapped in two similar towels the percentage moisture gain was much less than with drums. Loads steamed for longer than 10 minutes at 20 p.s.i. did not show a higher moisture gain than those steamed for 10 minutes. The weighing of a complete load is much more realistic than that of weighing towelling samples placed in the load as it gives some indication of the condition in which the whole load will be on delivery to the user. It is little comfort to either the surgeon or the 6 bacteriologist if the centre of a load is well dried but the outer layers are wet and therefore more vulnerable to $\stackrel{\infty}{-}$ bacterial penetration. The results obtained therefore confirm that once a pressure of $50 \mathrm{~mm}$. $\mathrm{Hg}$ absolute is reached the drying phase can be ended but they suggest that vacua of less than 26 in. $\mathrm{Hg}$, i.e., $100 \mathrm{~mm}$. $\mathrm{Hg}$ absolute, will produce a damp load if the dressings are contained in a drum. 
THE EFFECT OF A HEATED JACKET ON EFFICIENCY OF STEAM STERILIZATION

From time to time doubts have been cast on the advantages of having a steam-heated jacket round the chamber of a sterilizer. In the past such a jacket has probably acted as a steam separator where the chamber steam has been supplied from the jacket, but with a modern installation the steam supply should be dry before it reaches the sterilizer (M.R.C. report, 1959). A jacket increases the cost of a sterilizer and will be a source of steam wastage where there are long intervals between sterilizing cycles. Also where sterilization cycles follow one another rapidly it might be argued that a lagged chamber would be satisfactory as the walls would hold a considerable amount of heat. In order to see what would be the effect of the absence of a heated jacket on the performance of a sterilizer the experimental model was run with an unheated jacket. This would probably not be as efficient as a well-lagged chamber but would give some indication of what might be expected in a sterilizer without a jacket compared with the same sterilizer with a heated jacket.

Runs with the jacket cold were compared with similar runs where the jacket was heated. A load of 16 towels was used, the towels being packed so that they were in a vertical plane, parallel to the direction of steam entry. The results are shown in Fig. 4.

It can be seen that starting from cold even a highvacuum run was very slow, the load heating up less rapidly than that in a downward-displacement run with a heated jacket.
Even after the chamber had been heated by previous use there was a substantial delay in the heating up of a load compared with that when the jacket was heated. Jones and Finney (1960) noted that with a large nonjacketed sterilizer difficulty was experienced in drying the load until cast iron plates were placed in the sterilizer to provide more stored heat for the drying of dressings. Certainly during the drying part of the cycle and when the sterilizer is being unloaded and reloaded the chamber walls will cool so that only part of the heat taken up by the wall in one run will be available for the next.

The results suggest that a jacket is a good feature even in a high-vacuum sterilizer, except perhaps in those which are used infrequently and then with no degree of urgency.

\section{EFFICIENCY OF DOWNWARD-DISPLACEMENT STERILIZATION}

Downward-displacement sterilization has been the only method of steam sterilization (often used in conjunction with a partial fore-vacuum) in use in Britain until the recent introduction of high-vacuum sterilizers. However, many so-called sterilizers were faulty when examined (Bowie, 1955; Howie and Timbury, 1956) and it is only in recent times that many of these have been upgraded as suggested by Scott (1957). In correctly designed sterilizers, as noted by Walter (1948) and Perkins (1956), downward displacement of air works satisfactorily provided care is taken to pack the load so as to facilitate steam penetration. This is important as the difference in the specific gravity of air and steam is slight and the resulting force of

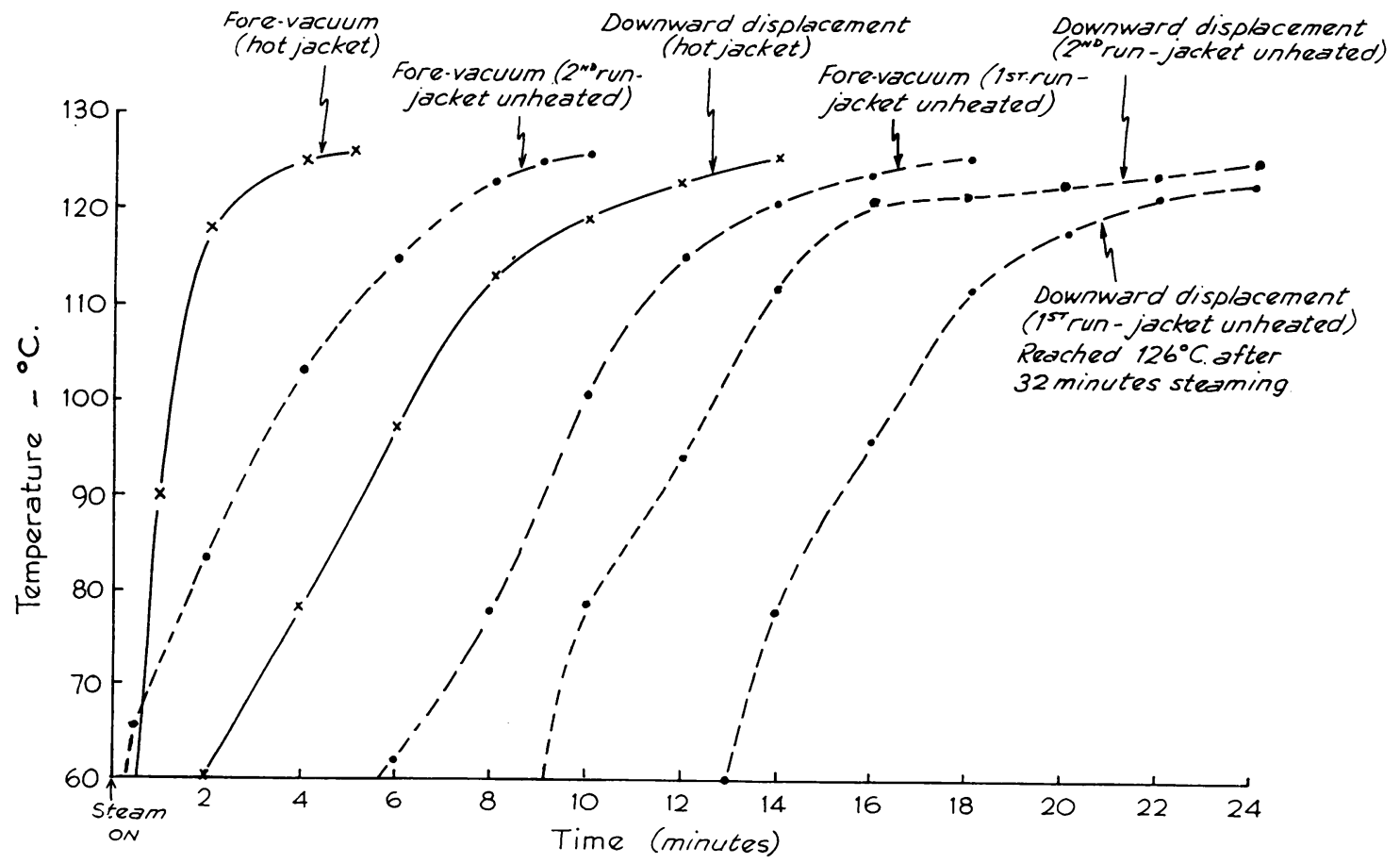

FIG. 4. Time taken for coolest part of load to reach $126^{\circ} \mathrm{C}$. 


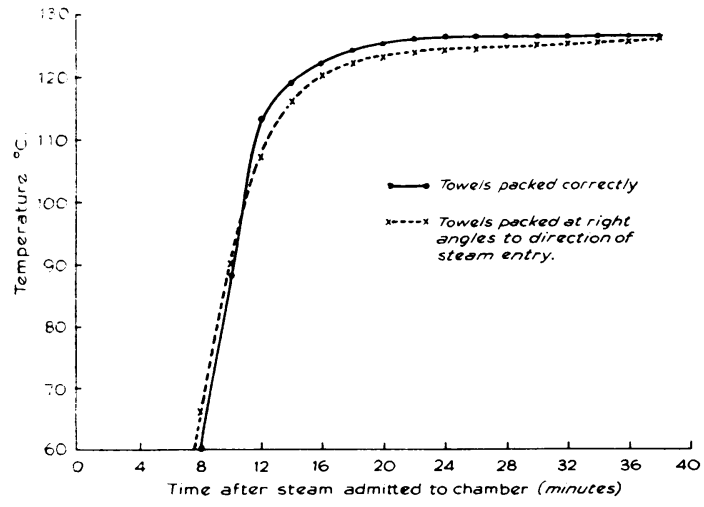

FIG. 5. Delay in steam penetration due to air pockets caused by incorrect position of load.

downward displacement is weak (M.R.C., 1959). It is easy to defeat downward displacement by, for instance, placing a drum on its base so that the holes for steam entry and air removal are at the side. Even the mere act of placing towels so that they lie in a horizontal rather than a vertical plane when placed in the sterilizer can delay steam penetration (Fig. 5). It is, however, not certain what will defeat downward displacement if the load is orientated correctly. An attempt was made, therefore, to define what load in a dressing drum, i.e., what degree of over-packing, would defeat downwarddisplacement sterilization. For this purpose different loads of cotton goods (towels or surgical gowns) were placed in a 10 in. $\times 9$ in. dressing drum and the time taken for the temperature to rise to $126^{\circ} \mathrm{C}$. was noted. When a weight of cotton was found which would prevent steam penetration so that the load would be at a temperature of $126^{\circ} \mathrm{C}$. for less than 10 of the 30 minutes allowed from the time the chamber drain temperature reached $126^{\circ} \mathrm{C}$. (the time recommended for the sterilization of dressings in drums in the M.R.C. report, 1959), an attempt was made to see how a similar weight of cotton wool would behave. It was found, however, that only about a third to one half of the weight of cotton wool could be packed into the drum and that this grossly delayed steam penetration. Hence it does not seem possible to define, in grams per c.c., what is an overpacked drum for cotton fibre. However, it was observed that quite full drums could be penetrated by steam but that as soon as a load was compressed on closing the drum lid steam penetration was seriously delayed (Fig. 6). Not only does such a delay mean that the right temperature is either reached slowly or not at all but it indicates the possibility of air pocketing, so that even if a temperature of $126^{\circ} \mathrm{C}$. was reached ultimately, there is a possibility that this may be inside a pocket of air which has reached the temperature of its surroundings. Therefore, all that can be said is that as long as a load of dressings is correctly orientated and not compressed, steam will

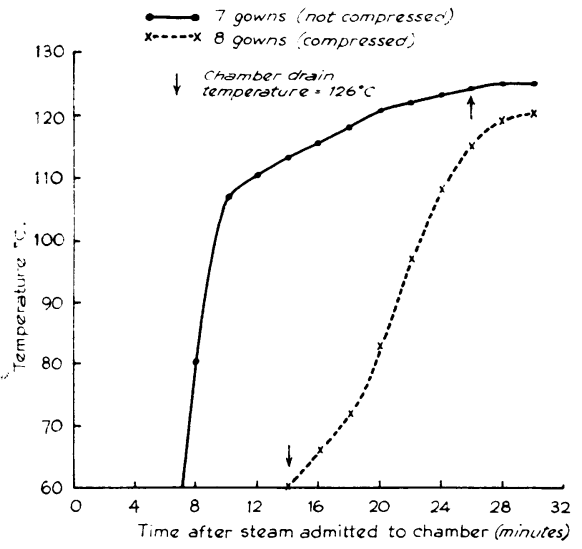

FIG. 6. Effect of compression of load on steam penetration. 옥 The temperature shown is that of the coolest part of the load.

penetrate it. These results were checked in a larger $\stackrel{\Phi}{\nexists}$ ( 9 c. ft.) sterilizer with a larger (10 in. $\times 14$ in.) dressing drum and there it was found that even when the towels were stacked one on top of another leaving a free space $\vec{\bullet}$ between them and the drum walls, if the pile was com- 9 pressed by the drum lid, penetration was delayed. The delay in penetration was as much as $\mathbf{1 5}$ minutes compared with a loosely packed drum. Conditions in a loosely packed drum were reflected well by the chamber drain thermometer, but, as found in experiments with different degrees of fore-vacuum, a chamber drain thermometer $\mathbb{D}$ will not always give an indication of slow penetration of steam into a load.

\section{DISCUSSION}

The most important finding in this study has been the confirmation of the work of Knox and Penikett: (1958) on the critical nature of the level of forevacuum which must be drawn in a high-vacuumc sterilizer in order to accomplish almost instantaneous steam penetration into a load. Where a temperature of $126^{\circ} \mathrm{C}$. is employed for sterilization, slight delay in steam penetration might be serious (using a $10 \frac{\mathrm{D}}{\mathrm{O}}$ minutes' holding period) but where a temperature of $134^{\circ} \mathrm{C}$. is used (three minutes' holding period) the slightest delay will almost certainly seriously impair the sterilization process. It is important therefore that not only should a high-vacuum sterilizer be specified to produce a fore-vacuum giving an absolute pressure of $20 \mathrm{~mm}$. Hg or less but that before it is accepted for use it must be tested with an accurate vacuum gauge to ensure that it is producing this vacuum. The incorporation of a pressure-stat toprevent the sterilization cycle from proceeding untif the correct level of vacuum has been reached is a com? mendable feature of commercial models available 
but periodic tests of a sterilizer should be designed to check on the accuracy of this component. The danger of an air leak which would allow air to enter the chamber after the fore-vacuum had been drawn is a real one and there is no doubt that the best way of countering such a possibility is to control the sterilization process by means of a monitored test drum. Such a test drum is described elsewhere (Fallon, 1961a) but the essential feature of it is that it cannot easily be penetrated by steam using downwards displacement and will therefore show at once any failure in the high-vacuum process. The importance of an adequate fore-vacuum cannot be overemphasized.

As stated in the second communication of the M.R.C. working party on pressure steam sterilizers (1960), high-vacuum sterilizers are, in general, proving satisfactory in practice. From the point of view of increased efficiency in speed of sterilization this is well described by Magee and Oakes (1958) and Alder and Gillespie (1959) where downward-displacement machines have been converted to high pre-vacuum working and by Wells and Whitwell (1960) with a small prototype high-speed, high-vacuum sterilizer.

The degree of after-vacuum is of some importance as the method of producing the vacuum depends upon the level required to dry dressings without any airing period. The findings here suggest that the system employed should be able to produce an after-vacuum to give a pressure of the order of $100 \mathrm{~mm}$. $\mathrm{Hg}$ absolute or better.

The difference in the results obtained by Penikett et $a l$. and those in this study are almost certainly due to the way in which the moisture content of the load was measured. In their work Penikett et al. measured the moisture content of towel samples which were always placed in exactly the same position (Penikett, personal communication), whereas I was concerned to measure the total moisture gain of a load in the belief that the total moisture content (which will be irregularly distributed throughout a load) is what matters to the user and also in the prevention of bacterial penetration of a load.

It is interesting to note that packs of dressings dry out more easily than dressings in drums. This is yet another good reason for using wrapped packs rather than dressing drums.

From the point of view of efficiency of sterilization there seems to be little doubt that a jacketed sterilizer has advantages over an unjacketed model and the small initial extra outlay will be well justified in terms of increased output of such a machine. Also condensation difficulties of the nature of those reported by Jones and Finney (1960) will be less in a jacketed sterilizer. (A number of commercial jacketed models do have a small pool of condensate lying on the bottom of the chamber after a cycle. This may be due to wet steam, an inner liner to the chamber which prevents all the condensate from reaching the hot chamber wall, or perhaps due to a chamber shape which does not aid the condensate to flow to the chamber drain.)

In downward-displacement sterilizers, steam penetration through a badly packed load will be delayed. Although bad packing cannot be defined precisely in measureable terms, users of such sterilizers must not only orientate the load correctly in relation to steam flow but must not in any way compress the contents of a dressing container. Here again wrapped packs have a great advantage over other containers in that they cannot easily be tightly compressed. They may, however, be of too great a size or have articles incorporated in them which would interfere with steam penetration (Perkins, 1956) and care must be taken to avoid these dangers. Some types of container used for surgical dressings may delay steam penetration when used in a downward-displacement sterilizer (Fallon, 1961b).

In any discussion of the efficiency of steam sterilization mention must be made of how to prevent recontamination of dressings. It is therefore relevant to re-emphasize the importance of the findings of the M.R.C. working party (1960) that spun glass filters are superior to those in current use on most sterilizers.

I am grateful to the Department of Health for Scotland for the sterilizer shell; the Board of Management for the Western Infirmary, Glasgow, for a grant from their endowment funds towards the cost of equipment; to $\mathrm{Mr}$. J. Wood, hospital engineer, and his staff, for their careful installation and maintenance of the sterilizer; to Dr. E. A. Bruges, Senior Lecturer in Mechanical Engineering, University of Glasgow, for advice on steam quality measurement, and to Mr. R. Callander for the diagrams.

\section{REFERENCES}

Alder, V. G.. and Gillespie, W. A. (1959). D.410, Drayton Regulator and Instrument Co., West Dravton, Middlesex.

Bowie, J. H. (1955). Pharm. J.. 174. 473.

Fallon, R. J. (1961a). J. clin. Path. In press.

- (1961b). Lancet, 2, 41.

Howie. J. W.. and Timbury, M. C. (1956). Ihid. 2, 669.

Jones. A. M., and Finney. J. (1960). Hosp Engr., 14, 122.

Knox, R. (1961). J. clin. Path., 14, 11.

- , and Penikett, E. J. K. (1958). Brit. med. J. , 1, 680.

Magee, K. C., and Oakes, H. E. (1958). Hosp. Engr., 12, 278.

Medical Research Council Working Party on Pressure-Steam Sterilizers (1959). Lancet, 1, 425.

Penikett, E. J. K., Rowe, T. W., and Robson, E. (1958). J. appl. Bact, 21. 282.

Perkins, J. J. (1956). Principles and Methods of Sterilization. Thomas, Springfield, Illnois.

Scott, A. C. (1957). Lancet, 2, 633.

Walter. C. W. (1948). The Aseptic Treatment of Wounds. Macmillan, New York.

Wells, C.. and Whitwell, F. R. (1960). Lancet, 2, 643. 